\title{
Apoptosis in neural development and disease
}

\author{
Nicholas D Mazarakis, A David Edwards, Huseyin Mehmet
}

\section{Introduction}

Neural cell death has a pivotal role in both the development and pathophysiology of the nervous system. Two distinct modes of cell deathnecrosis and apoptosis - are involved in pathological neuronal loss, but apoptosis alone is the mechanism of programmed cell death during development. All cells will undergo apoptosis in the absence of survival signals, usually peptide growth factors secreted by other cells. This provides an elegant mechanism for the control of neuronal development: a surplus of neurons is produced, and only those that form the correct connections with the target tissue receive adequate survival factors. The remainder undergo apoptotic death and removal. Apoptosis continues throughout life and is the central mechanism for the removal of surplus, unwanted, damaged or aged cells. Dysregulation of apoptosis is seen after cellular insults or in neurodegeneration as well as in tumourigenesis. Strategies which influence the apoptotic pathway offer valuable therapeutic approaches in a variety of pathological states.

\section{Apoptosis}

The term programmed cell death was first used by Lockshin and Williams in 1964, to describe the pre-determined loss of specific cells during insect metamorphosis by an intrinsic cellular suicide programme. ${ }^{1}$ In a seminal paper Kerr, Wyllie, and Currie $^{2}$ later coined the word apoptosis to describe this form of death and went on to show that it was a widespread process in nature, occurring both during normal physiological development and in many pathological conditions.

Apoptosis is a well conserved and highly regulated mechanism of cell death for the removal of unnecessary, surplus, aged or damaged cells. Dysregulation of apoptosis can result in the persistence of mutated cells, leading to malformations, autoimmune disease, and cancer. On the other hand, inappropriate apoptosis resulting in the removal of healthy cells can occur in diseases such as infection, hypoxic-ischaemic injury, neurodegenerative or neuromuscular diseases, and AIDS.

Apoptosis can be distinguished from necrotic cell death ${ }^{3}$ : in necrosis, a cell's demise is precipitated by an external insult and involves the early loss of membrane integrity, with damage to organelles and the leakage of cytoplasmic contents, leading to the recruitment of phagocytes with an acute inflammatory reaction. In contrast, apoptosis is cellular suicide. Cells dying by apoptosis retain membrane and organelle function until late in the process, while developing plasma membrane blebbing, reduced cytoplasmic volume, chro- matin condensation and nuclear fragmentation. In the final stages cellular fragments wrapped in plasma membrane bud off as apoptotic bodies which are subsequently phagocytosed by healthy neighbouring cells. ${ }^{4}$ The elimination of cell debris occurs in the absence of an inflammatory response, and this quiet, rapid, and efficient removal of apoptotic cells means that apoptosis can be difficult to detect in tissue: although as many as $50 \%$ of the cells in a developing organ may undergo apoptosis, less than $1 \%$ of cells are apoptotic at any one time.

\section{Apoptosis in the developing nervous system}

Programmed cell death by apoptosis occurs in many developmental processes, including body sculpting (such as digit formation), elimination of self-reacting immune cells, sexual organ development and gamete formation. ${ }^{5}$ Indeed, a general principle of development in multicellular organisms is emerging: excess numbers of cells are made, and then surplus or unwanted cells are removed by apoptosis during the formation of functional organs.

In the developing nervous system apoptosis is observed as early as neural tube formation and persists throughout terminal differentiation of the neural network. The emergence of the neurotrophic hypothesis from the pioneering work of Levi-Montalcini, Hamburger, and Cohen ${ }^{6}$ established that more than $50 \%$ of neurons are lost during development as a result of limiting trophic support from the target tissue they are destined to innervate. This neuronal attrition, which ensures appropriate connections in the central and peripheral nervous systems, was subsequently shown to be effected by the induction of apoptosis in unwanted cells.

A growing number of neurotrophic factors, such as the nerve growth factor family, the neurokines, and growth factors such as insulin-like growth factors (IGF-I and IGF-II)support the survival of particular types of neurons. ${ }^{7-10}$ Targeted disruption of genes encoding these factors or their receptors indicates that particular neurotrophic factors are important for the development of specific neuronal populations. ${ }^{11}$

Neurotrophic factors function by binding to specific receptors in the cell membrane, and the effects of NGF offer an example of the subtle control that the system allows. The nerve growth factor receptor has high and low affinity components. It will function as a survival factor if it binds to the high affinity trkA receptor, but will induce apoptosis of retinal neurons ${ }^{12}$ or oligodendrocytes ${ }^{13}$ when it binds to the low affinity receptor p75 in the 


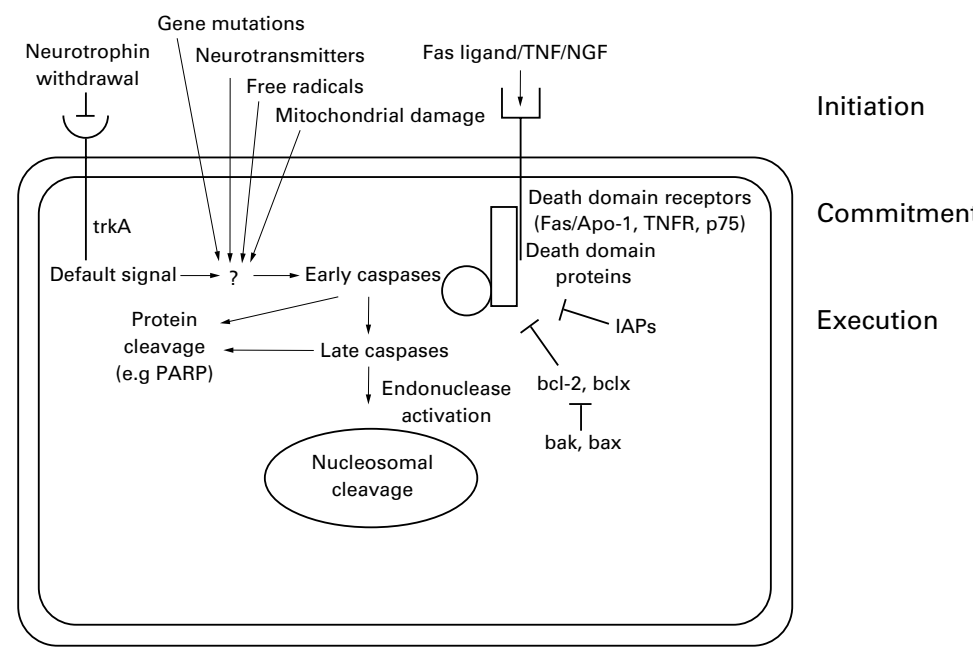

Figure 1 A model of apoptosis in neural cells. Neurotrophin withdrawal leads to death by a default mechanism through as yet uncharacterised pathways. Gene mutations, inappropriate production of neurotransmitters, such as glutamate, free radical generation, and mitochondrial damage also trigger apoptosis as do engagement of death receptors. In the latter case oligomerisation of Fas/Apo-1 or TNF receptors or the $p 75$ NGF receptor results in the recruitment of death domain proteins, which in turn activate members of the caspase family of cysteine proteases in an organised proteolytic cascade. Bcl-2 family members and inhibitor of apoptosis proteins (IAPs) control the decision to commit cell suicide, depending on whether pro- or anti-apoptotic partners predominate. In the later stages, specific endonucleases cleave DNA as part of the packaging process. Finally, cells are phagocytosed by healthy neighbours (not shown). Arrows indicate the flow of events and do not necessarily denote direct interactions.

absence of trkA. Nerve growth factor in the extracellular environment is thus able to control neural development by both promoting growth of some cell types and the elimination of others. ${ }^{14}$

In some cases, however, targeted genetic disruption of neurotrophic factors or their receptors can leave the central nervous system apparently unaffected, suggesting that these factors are functionally redundant..$^{15}$ It is now evident that the control of neuronal survival does not only depend on the provision of trophic molecules by the targets but also on activity, humoral factors, and trophic support from glia. ${ }^{16}$

It is not only neurons that undergo programmed cell death during differentiation. Apoptosis seems to regulate cell numbers in systems as diverse as the disappearance of the germinal layer during the third trimester of pregnancy ${ }^{17}$; the sexual differentiation of the medial preoptic nucleus, where apoptosis is controlled by testosterone ${ }^{18}$; lineages if the olfactory epithelium ${ }^{19}$; oligodendrocyte development in the optic nerve ${ }^{20}$; and the development of Schwann cells in the periperhal nervous system. ${ }^{21}$

\section{Mechanisms of apoptosis}

All metazoan cells, from the early blastocyst to terminally differentiated neurons, will undergo apoptosis if deprived of survival factors, suggesting that death not survival is the default fate. ${ }^{22}$ It follows that the apoptotic machinery must be permanently in place and poised to act. Consistent with this, in many cases apoptosis can proceed in the absence of new gene transcription or protein synthesis.

The apoptotic programme can be broadly divided into three major stages: initiation; commitment; and execution (fig 1). While the initiation step can be triggered by multiple stimuli, the commitment and execution steps appear to be more stereotyped.

Apoptosis can be initiated by diverse signals, including the withdrawal of survival signals, exposure to pro-apoptotic stimuli such as DNA damage, reduced intracellular ATP concentrations, or binding of ligands to specific receptors in the plasma membrane. Several such "death" receptors have been defined, including p75, Fas/APO-1, and the tumour necrosis factor (TNF) receptor. ${ }^{23}$ Signal transduction from these receptors is mediated through a growing family of adaptor molecules that either directly or indirectly activate the enzymes that begin the dismantling of cell proteins and nucleic acids. In the case of Fas/APO-1, ligand binding induces receptor oligomerisation and subsequent binding of the Fas associating death domain protein, FADD. This molecule in turn recruits FLICE (FADD-like ICE), a member of the caspase family of proteases involved in orchestrating the apoptotic programme. ${ }^{23}$

After the initiation of the apoptotic programme commitment to apoptosis is not immediate. The time at which a cell becomes irreversibly committed to death can vary from a few minutes to several hours or longer. ${ }^{24}$ The decision to commit is affected by a delicate balance between pro- and anti-apoptotic forces within the cell. Many of the participants in the apoptotic cascade have opposing partners, so that the decision to live or die depends on whether pro- or anti-apoptotic signals are dominant. A growing number of second messengers have also been implicated in regulating the apoptotic process. These include protein kinase $\mathrm{C}$ cyclic $\mathrm{AMP}$, calcium, and ceramide. ${ }^{25}$ Until commitment is made, the outcome can be influenced by manipulation of these forces, and the process is subject to regulation. However, commitment marks a point of no return when anti-apoptotic intervention ceases to be effective. ${ }^{26}$

The opposing aspects of cell survival and death are illustrated by the bcl-2 family of proteins. These genes are homologous to the antiapoptotic gene, ced-9, identified in the nematode $C$ elegans as an upstream inhibitor of the pro-apoptotic genes ced-3 and ced- 4 . In mammalian cells the bcl-2 family includes both anti-apoptotic proteins, such as bcl- $\mathrm{x}_{1}$ and bcl-2 itself, and their pro-apoptotic partners, including bax and bad. ${ }^{27} \mathrm{Bcl}-2$ family members can form heterodimers with each other and it is the antagonistic balance between bcl-2/ bcl- $\mathrm{x}_{1}$ and bax / bad which controls the cellular decision to live or commit suicide. Bcl-2 was originally identified in chromosomal translocations in follicular lymphoma, ${ }^{28}$ and this family of proteins also has a role in neuronal apoptosis. Although bcl-2 deletion in transgenic mice is not lethal and has no neuronal phenotype at birth ${ }^{29}$ substantial degeneration of motor, sensory, and sympathetic neurons occurs after the physiological cell death period. This suggests that bcl-2 is not a neurodevelopmental survival signal but is crucial for the maintenance of specific populations of neurons during the early postnatal period. In accordance with this, bcl-2 
overexpression has been shown to protect mice against ischaemic stroke. ${ }^{30}$ On the other hand, bcl- $x_{1}$ null mice die on embryonic day 13 with massive neuronal death in the brain and spinal cord, suggesting that this member of the bcl-2 superfamily is essential for normal neuronal development. ${ }^{31}$

One of the earliest signals in the apoptotic cascade is the activation of specific cysteine proteases that cleave at aspartate residues, now collectively called caspases. ${ }^{32}$ Caspase activation occurs by proteolytic cleavage of the pro-enzyme. For example, caspase-1 (also known as ced-3 or interleukin-1 $\beta$-converting enzyme (ICE)), is of primary importance because it activates at least two downstream caspases. $^{33}$ The caspases thus constitute an amplification mechanism for apoptotic signals. They are activated soon after the death trigger and cleave specific cellular targets, such as the DNA repair enzyme poly-ADP-ribose polymerase, presumably in preparation for ultimate cellular degradation. The importance of these enzymes in neuronal survival is illustrated by transgenic experiments where overexpression of a dominant negative caspase protects mice from cerebral ischaemia. ${ }^{34}$

Recent work has emphasised the role of mitochondria in the regulation of apoptosis. ${ }^{35}$ Bcl-2 family genes and ced- 4 are located on the outer mitochondrial membrane, and genetic deletion of the membrane binding domains from the protein sequence attenuates their function. The release of cytochome-c from mitochondria is required for execution to proceed in some cell lines, and mitochondria in apoptotic cells also release a pro-apoptotic peptide, apoptosis inducing factor. It has thus been suggested that the mitochondrion is the central control point of apoptotic execution, and that the opening of channels in the inner mitochondrial membrane, to cause the mitochondrial membrane permeability transition, is the final common pathway to apoptotic death. This hypothesis has several points in its favour, not least in offering an explanation of how cellular insults such as hypoxia-ischaemia can cause both apoptosis and necrosis.

In the late stages of apoptotic execution the organised degradation of genomic DNA is carried out by unidentified endonucleases. The activation of these enzymes is concurrent with, or immediately consequent on, caspase activation, although the precise mechanisms are as yet unknown. The end result of endonuclease activation is the internucleosomal cleavage of DNA, first leading to high molecular weight fragments (50 to $300 \mathrm{~kb}$ ), and eventually to characteristic DNA "ladders" that can be detected by gel electrophoresis. ${ }^{36}$

\section{Methods for detecting apoptosis}

As both apoptosis and necrosis can occur simultaneously, it has become increasingly important to distinguish between these two modes of cell death. Differences can be observed by light or electron microscopy, and no other method for distinguishing apoptosis from necrosis has been shown to be as reliable as morphological analysis using appropriate stains. However, a variety of methods are in use, including: fluorescence activated cell sorting $^{37}$; detection of DNA fragmentation, either by agarose gel electrophoresis which demonstrates characteristic "ladders"38; or the terminal deoxytransferase mediated biotin dUTP nick end-labelling (TUNEL) and in situ end labelling (ISEL) techniques which use DNA polymerase to repair DNA nicks with labelled nucleotides. ${ }^{39}$

\section{Apoptosis in nervous system injury and disease}

Although apoptosis is involved in a number of diseases of the nervous system, ${ }^{40}$ in most cases the link between a specific mutation or injury and the activation of apoptotic cascades remains elusive. A summary of a growing list of neurological diseases in which apoptosis has been implicated as an important pathological mechanism is given below.

NEURONAL INJURY

Cerebral hypoxic-ischaemic injury is a significant cause of death and neurological impairment. Magnetic resonance spectroscopy studies have shown that transient hypoxiaischaemia leads to a biphasic disruption of cerebral energy metabolism. Related to this biphasic energy failure, two waves of cell death seem to follow hypoxic-ischaemic injury in the developing brain. Immediate neuronal death is probably largely due to necrosis, resulting mainly from the accumulation of calcium ions, leading to membrane pump failure. ${ }^{41}$ Delayed cell death resulting from hypoxic-ischaemic injury seems to involve different or additional mechanisms and a growing body of data suggests that in the delayed phase of injury cell death occurs by apoptosis. ${ }^{42} 43$ The amount of apoptosis is directly related to the magnitude of ATP depletion during hypoxia-ischaemia. ${ }^{42}{ }^{44}$ Significant amounts of apoptosis have been observed in the brains of newborn infants following both birth asphyxia and sudden intrauterine death ${ }^{45}$ and apoptosis is also prominent in white matter injury in newborn infants. There is evidence that apoptosis may continue for many weeks after an hypoxicischaemic insult, ${ }^{46}$ and this may be related to the persistent changes in cerebral energy metabolism seen in infants during the months following birth asphyxia. ${ }^{47}$

Following focal neural injury, apoptosis has been detected in sites distant from the initial damage. After acute spinal cord injury in monkeys apoptosis of oligodendrocytes occurs in remote degenerating fibre tracts, ${ }^{48}$ and after forebrain injury in developing rats apoptosis can be observed in the cerebellum. ${ }^{49}$ The apoptotic loss of oligodendrocytes could thus be a possible cause of secondary demyelination in paraplegia and in the chronic degeneration associated with multiple sclerosis. Further evidence for a role for apoptosis in this type of injury comes from the report that bcl-2 expression promotes the growth and regeneration of retinal axons. ${ }^{50}$ 
NEURAL CANCERS

An intimate connection between apoptosis and the cell cycle has been shown in carcinogenesis: proto-oncogenes such as c-fos, c-jun, and c-myc can trigger apoptosis and promote cell division, while inactivation of the pro-apoptotic p53 tumour suppressor gene is a frequent marker of human neoplasia. ${ }^{51}$ For example, in a number of gliomas the loss of wild p53 activity has been linked to tumour progression, possibly resulting in resistance to chemotherapy and radiotherapy. Although there have been reports of bcl-2 overexpression in glioma cell lines, the correlation between the anti-apoptotic effect of this gene and malignancy is not clear. However, a homologue of bcl-2, the brain related apoptosis gene (BRAG-1), is found predominantly in the brain, and is upregulated in human gliomas as a rearranged transcript. ${ }^{52}$

INFECTIOUS DISEASE

Apoptosis may have a role in HIV encephalopathy. In the brain the virus replicates primarily in microglia which it enters via the CD4 receptor. ${ }^{53}$ Although the activation of microglia is thought to be the primary cause of neuronal loss and demyelination, neurons die by apoptosis in HIV encephalopathies perhaps due to HIV mediated alterations in astrocyte function and aberrant stimulation of NMDA receptors, or by the accumulation of nitric oxide following the activation of inducible nitric oxide synthase..$^{33}$

In subacute sclerosing panencephalitis widespread apoptotic death has been detected in the brain, ${ }^{54}$ although no correlation was observed between viral load, lymphocyte infiltration, and the number of apoptotic cells. DNA fragmentation indicative of apoptosis has been detected in scrapie infected sheep ${ }^{55}$ and mouse $\mathrm{e}^{56}$ brain, suggesting a role for this mode of cell death in spongiform encephalopathies.

NEURODEGENERATION

Spinal muscular atrophy is associated with mutations in the survival of motor neuron and neuronal apoptosis inhibitory protein (NAIP) genes. ${ }^{5758}$ NAIP is related to the baculovirus inhibitor of apoptosis protein and inhibits apoptosis in several cell types. ${ }^{59}$ This implies that mutations in NAIP could deregulate apoptosis in spinal motor neurons, thus causing their death. The general importance of anti-apoptotic genes in neuronal protection is emphasised by recent reports that NAIP overexpression can also rescue neurons after cerebral ischaemia.

Apoptosis has also been implicated in retinal dystrophies such as retinitis pigmentosa. In this instance, apoptosis results from mutations in any one of the three photoreceptor genes rhodopsin, peripherin, and the $\beta$-subunit of cyclic guanosine monophosphate diesterase, resulting in photoreceptor degeneration. ${ }^{60} \mathrm{Al}-$ though the apoptotic trigger is unknown, absence of c-fos prevents apoptosis in these cells. ${ }^{61}$ Moreover, defined neurotrophins and growth factors injected intraocularly in animal models of retinal degeneration enhance photoreceptor survival, implying that the apoptotic cascade can be blocked by supplying exogenous survival signals. ${ }^{62}$

The mutation underlying Huntington's disease is an expanded trinucleotide repeat within a novel gene, huntingtin, that is crucial for normal development and can be regarded as a cell survival gene. ${ }^{63}$ Transgenic models null for the huntingtin gene show increased apoptosis in neurons of the embryonic neuroectoderm. ${ }^{64}$ Moreover, huntingtin is specifically cleaved during apoptosis by caspase-3 (apopain) and the rate of cleavage is enhanced by a gain of function associated with the triplet expansion. ${ }^{65}$ This is also supported by the observation that overexpression of the specific trinucleotide repeats in transgenic mice is sufficient to induce the Huntington's phenotype. ${ }^{66}$

Most cerebellar ataxias are associated with neuronal loss. Ataxia telangectasia, caused by mutations in the ATM gene, is thought to have an apoptotic component. ATM shares extensive and important homology with the DNA dependent protein kinases involved in DNA damage responses at different cell cycle check points, and is downregulated in all patients with ataxia telangectasia. ${ }^{67}$ The fact that inappropriate $\mathrm{p} 53$ mediated apoptosis is the major cause of death in ataxia telangectasia cells irradiated in culture ${ }^{68}$ suggests that the mutation causes inappropriate triggering of apoptosis by otherwise non-lethal DNA damage.

In the familial form of amyotrophic lateral sclerosis gain of function mutations in the gene encoding copper zinc superoxide dismutase (sod-1) create a dominant pro-apoptotic signal. ${ }^{69}$ Although cell injury by accumulation of free radicals can trigger apoptosis, these mutants can induce apoptosis both in neural cells in culture and in transgenic mice..$^{70}$

Mental retardation in Down's syndrome has also been linked to inappropriate apoptosis. Although cortical neurons from fetal Down's syndrome brains differentiate normally in culture, they subsequently degenerate and undergo apoptosis. ${ }^{72}$ Degeneration is blocked by treatment with free radical scavengers, suggesting that a defect in metabolism of reactive oxygen species is the trigger for apoptosis.

In Parkinson's disease the death of dopaminergic neurons in the substantia nigra has been shown to occur by apoptosis and can be blocked by delivery of glial derived neurotrophic factor. ${ }^{73}$ Alzheimer's disease is associated with the progressive accumulation of $\beta$-amyloid protein which is the major component of neural plaques. ${ }^{74}$ The $\beta$-amyloid peptide can induce neurons to undergo apoptosis in vitro. ${ }^{75}$

\section{INHERITED METABOLIC DISEASES}

There are some data to suggest that the acute encephalopathy associated with maple syrup urine disease is due to the induction of apoptosis by an accumulating metabolite of leucine, $\alpha$-keto isocaproic acid. ${ }^{76}$ This compound is a potent inducer of apoptosis in central nervous system glial cells in culture, and the effect is enhanced in the presence of leucine. Phenylalanine and leucine alone do not induce 
apoptosis in this system, suggesting that this effect is specific (unpublished obervations).

\section{Therapeutic manipulation of the apoptotic programme}

INHIBITION OF APOPTOSIS

As apoptosis is a highly regulated physiological process, a window of opportunity exists for therapeutic intervention. However, if antiapoptotic strategies are to be successful, first it must be established that apoptosis is a major component leading to the neuronal defecit, second that inhibition of cell death does not result in the persistence of damaged neurons, and third, that the anti-apoptotic treatment can be applied before the cellular commitment to apoptosis.

Several anti-apoptotic agents reduce neuronal loss following cerebral ischaemia. Both IGF- $1^{77}$ and the protein synthesis inhibitor cycloheximide $^{78}$ reduce cerebral injury if administered soon after hypoxia-ischaemia. Similarly, administration of a peptide inhibitor of caspase activity (z-VAD-DCB) substantially reduces infarct volume resulting from focal cerebral ischaemia in rats. ${ }^{79}$ Our own studies have shown that mild hypothermia applied immediately after cerebral hypoxia-ischaemia prevents neural apoptosis without affecting the amount of necrosis. ${ }^{80}$ Inhibitors of neuronal apoptosis also have therapeutic value in neural trauma. Neurotrophins directly introduced into cetnral nervous system lesions rescue degenerating neurons, ${ }^{81}$ suggesting a possible therapeutic intervention for neurodegeneration and paraplegia. In this respect, targeted delivery of normal alleles to replace mutated genes or anti-apoptotic genes, to enhance survival of degenerating neurons, is the long term goal of gene therapy. ${ }^{82}$

\section{INDUCTION OF APOPTOSIS}

The anti-tumour effect of radiotherapy and chemotherapy is effected through the induction of apoptosis in tumour cells. However, the considerable side effects of these pro-apoptotic treatments have led to the search for novel methods for promoting tumour apoptosis. Brain tumours have been treated successfully using the herpes thymidine kinase-gancyclovir gene therapy approach which works by targeting dividing cells in a non-proliferating environment ${ }^{83}$; several clinical trials are now underway in humans. As gliomas respond well to Fas/Apo-1 mediated induction of apoptosis ${ }^{84}$ this could also lead to the development of a therapeutic intervention.

In summary, there is accumulating evidence for the role of neuronal apoptosis in diseases of the nervous system. Researchers are now looking forward to the exciting prospect of developing effective therapeutic strategies based on the manipulation of this physiological process.

We are grateful to the Weston Foundation for their continued financial support.

1 Lockshin RA, Williams CM. Programmed cell death II Endocrine potentiation of the breakdown of the intersegmental muscles of silkmoths. F Insect Physiol 1964;10:643-
2 Kerr JF Wyllie AH, Currie AR. Apoptosis: a basic biological phenomenon with wide-ranging implications in tissue phenomenon with wide-ranging im
kinetics. Br f Cancer 1972;26:239-57.

3 Majno G, Joris I. Apoptosis, oncosis, and necrosis. An overview of cell death. Am $\mathcal{F}$ Pathol 1995;146:3-15.

4 Wyllie AH, Duvall E. Cell injury and death. In: Mcgee JO'D, Isaacson PG, Wright NA, eds. Oxford Textbook of Pathology. Oxford: Oxford University Press, 1992:141-93.

5 Jacobson MD, Weil M, Raff MC. Programmed cell death in animal development. Cell 1997;88:347-54

6 Oppenheim RW. Cell death during development of the nervous system. Ann Rev Neurosci 1991;14:453-501.

Lindsay RM. Neuron saving schemes Nature 1995; 373:289-90.

8 Kotzbauer PT, Lampe PA, Heuckeroth RO, et al. Neurturin, a relative of glial-cell-line-derived neurotrophic factor. Nature 1996;384:467-70.

9 Ebens A, Brose K, Leonardo ED, et al. Hepatocyte growth factor/scatter factor is an axonal chemoattractant and a neurotrophic factor for spinal motor neurons. Neuron 1996;17:1157-72

10 Sendtner M, Gotz R, Holtmann B, et al. Cryptic physiological trophic support of motoneurons by LIF revealed by double gene targeting of CNTF and LIF. Curr Biol 1996; 6:686-94.

11 Snider WD. Functions of the neurotrophins during nervous system development: what the knockouts are teaching us. Cell 1994;77:627-38.

12 Frade JM, Rodriguez-Tebar A, Barde YA. Induction of cell death by endogenous nerve growth factor through its p75 receptor. Nature 1996;383:166-8.

13 Casaccia-Bonnefil P, Carter BD, Dobrowsky RT, Chao MV. Death of oligodendrocytes mediated by the interaction of nerve growth factor with its receptor p75. Nature 1996;383:716-19

14 Bredesen DE, Rabizadeh S. p75NTR and apoptosis: Trk-dependent and Trk-independent effects. Trends Neurosci 1997;20:287-90.

15 Johnson J, Oppenheim R. Keeping track of changing neurotrophic theory. Curr Biol 1994;4:662-5.

16 Raff MC, Barres BA, Burne JF, Coles HS, Ishizaki Y, Jacobson MD. Programmed cell death and the control of cell survival: lessons from the nervous system. Science 1993;262:695-700.

17 Volpe JJ. Neuronal proliferation, migration, organization and myelination. In: Neurology of the newborn. 3rd Edn. and myelination. In: Neurology of the new

18 Davis EC, Popper P, Gorski RA. The role of apoptosis in sexual differentiation of the rat sexually dimorphic nucleus of the preoptic area. Brain Res 1996;734:10-18.

19 Holcomb JD, Mumm JS, Calof AL. Apoptosis in the neuronal lineage of the mouse olfactory epithelium: regulation in vivo and in vitro. Dev Biol 1995;172:307-23.

20 Barres BA, Hart IK, Coles HS, et al. Cell death and control of cell survival in the oligodendrocyte lineage. Cell 1992;70:31-46.

21 Ciutat D, Caldero J, Oppenheim RW, Esquerda JE. Schwann cell apoptosis during normal development and after axonal degeneration induced by neurotoxins in the chick embryo. F Neurosci 1996;16:3979-90.

22 Raff MC. Social controls on cell survival and cell death. Nature 1992;356:397-400.

23 Nagata S. Apoptosis by death factor. Cell 1997;88:355-65. 4 Evan GI. Old cells never die, they just apoptose. Trends Cell Biol 1994;4:191-2.

25 Hale AJ, Smith CA, Sutherland LC, et al. Apoptosis: molecular regulation of cell death. Eur $\mathcal{f}$ Biochem 1996;236:1-26.

26 McCarthy NJ, Whyte MK, Gilbert CS, Evan GI. Inhibition of Ced-3/ICE-related proteases does not prevent cell death induced by oncogenes, DNA damage, or the Bcl-2 homologue Bak. f Cell Biol 1997;136:215-27.

27 Reed JC. Double identity for proteins of the Bcl-2 family. Nature 1997;387:773-6.

28 Tsuijimoto Y, Croce CM. Analysis of the structure, transcripts, and protein products of bcl-2, the gene involved in human follicular lymphoma. Proc Natl Acad Sci USA 1986;83:5214-18.

29 Michaelidis TM, Sendtner M, Cooper JD, et al. Inactivation of bcl-2 results in progressive degeneration of motoneurons, sympathetic and sensory neurons during early postnatal development. Neuron 1996;17:75-89.

30 Martinou JC, Dubois-Dauphin M, Staple JK, et al. Overexpression of BCL-2 in transgenic mice protects neurons from naturally occurring cell death and experimental ischemia. Neuron 1994;13:1017-30.

31 Motoyama N, Wang F, Roth KA, et al. Massive cell death of immature hematopoietic cells and neurons in Bcl-ximmature hematopoietic cells and neuror

32 Alnemri ES, Livingston DJ, Nicholson DW, et al. Human ICE/CED-3 protease nomenclature Cell 1996;87:171.

33 Takahashi A, Earnshaw WC. ICE-related proteases in apoptosis. Curr Opin Genet Dev 1996;6:50-5.

34 Friedlander RM, Gagliardini V, Hara H, et al. Expression of a dominant negative mutant of interleukin-1 beta converting enzyme in transgenic mice prevents neuronal cell death induced by trophic factor withdrawal and ischemic brain injury. $\mathcal{F}$ Exp Med 1997; 185:933-40.

35 Kroemer G. The proto-oncogene $\mathrm{Bcl}-2$ and its role in regulating apoptosis. Nature Med 1997;3:614-20

36 Peitsch MC, Mannherz HG, Tschopp J. The apoptosis endonucleases: cleaning up after cell death? Trends Cell Biol 1994;4:37-41. 
37 Ormerod MG, Sun X-M, Brown D, Snowden RT, Cohen GM. Quantification of apoptosis and necrosis by flow
cytometry. Acta Oncologica 1994;32:417-24.

38 Wyllie AH. Glucocorticoid-induced thymocyte apoptosis is associated with endogenous endonuclease activation. Nature 1980;284:555-6.

39 Gavrieli Y, Sherman Y, Ben Sasson SA. Identification of programmed cell death in situ via specific labelling of nuclear DNA fragmentation $\mathcal{F}$ Cell Biol 1992;119:493-501.

40 Thompson CB. Apoptosis in the pathogenesis and treatment of disease. Science 1995;267:1456-62.

41 Edwards AD. Protection against hypoxic-ischaemic cerebral injury in the developing brain Perfusion 1993;8:97-100.

42 Mehmet H, Edwards AD. Hypoxia, ischaemia, and apoptosis. Arch Dis Child 1996;75:73-5.

43 Choi DW. Ischemia-induced neuronal apoptosis. Curr Opin Neurobiol 1996;6:667-72.

44 Mehmet H, Yue X, Squier MV, et al. Increased apoptosis in the cingulate sulcus of the newborn piglet following tranthe cingulate sulcus of the newborn piglet following tran-
sient hypoxia-ischaemia is related to the degree of high sient hypoxia-ischaemia is related to the degree of high
energy phosphate depletion during the insult. Neurosci Lett 1994;181:121-5.

45 Edwards AD, Yue X, Cox P, et al. Apoptosis in the brains of infants suffering intrauterine cerebral injury. Pediatr Res (in press)

46 Du C, Hu R, Csernansky CA, Hsu CY, Choi DW. Very delayed infarction after mild focal cerebral ischemia: a role for apoptosis? F Cereb Blood Flow Metab 1996;16:195-201

47 Robertson NJ, Cox IJ, Counsell S, Cowan F, Azzopardi D, Edwards AD. Persistent lactate following perinatal hypoxic-ischaemic encepalopathy and its relationship to energy failure studied by magnetic resonance spectroscopy. Early Hum Devel (in press).

48 Crowe MJ, Bresnahan JC, Shuman SL, Masters JN, Beattie MS. Apoptosis and delayed degeneration after spinal cord injury in rats and monkeys. Nature Med 1997;3:73-6.

49 Joashi U, Edwards AD, Cox P, Kozma M, Greenwood K, Mehmet H. Poly(ADP-ribose) polymerase cleavage precedes apoptosis in the cerebellum following hypoxiacedes apoptosis in the cerebellum

50 Chen DF, Schneider GE, Martinou JC, Tonegawa S. Bcl-2 promotes regeneration of severed axons in mammalian promotes regeneration of severe

51 Evan GI, Harrington E, McCarthy N, et al. Integrated control of cell proliferation and apoptosis by oncogenes In Thomas NSB, ed. Apoptosis and cell cycle control in cancer. Oxford: BIOS, 1996:109-29.

52 Das R, Reddy EP, Chatterjee D, Andrews DW. Identification of a novel Bcl-2 related gene, BRAG-1, in human glioma. Oncogene 1996;12:947-51.

53 Dubois-Dalcq $M$, Altmeyer R, Chiron M, Wilt S. HIV interactions with cells of the nervous system. Curr Opin Neurobiol 1995;5:647-55.

54 McQuaid S, McMahon J, Herron B, Cosby SL. Apoptosis in measles virus-infected human central nervous system
tissues. Neuropath Appl Neurobiol 1997;23:218-24.

55 Fairbairn DW, Carnahan KG, Thwaits RN, Grigsby RV Holyoak GR, O'Neill KL. Detection of apoptosis induced Holyoak GR, O'Neill KL. Detection of apoptosis induced
DNA cleavage in scrapie-infected sheep brain. FEMS Microbiol Lett 1994;115:341-6.

56 Giese A, Groschup MH, Hess B, Kretzschmar HA. Neuronal cell death in scrapie-infected mice is due to apoptosis. Brain Pathol 1995;5:213-21.

57 Lefebvre S, Burglen L, Reboullet S, et al. Identification and characterization of a spinal muscular atrophy-determining gene. Cell 1995;80:155-65.

58 Roy N, Mahadevan MS, McLean M, et al. The gene for neuronal apoptosis inhibitory protein is partially deleted in individuals with spinal muscular atrophy Cell 1995;80:167-78

59 Liston P, Roy N, Tamai K, et al. Suppression of apoptosis in mammalian cells by NAIP and a related family of IAP genes. Nature 1996;379:349-53.

60 Chang GQ, Hao Y, Wong F. Apoptosis: final common pathway of photoreceptor death in rd, rds, and rhodopsin

61 Hafezi F, Steinbach JP, Marti A, et al. The absence of c-fos prevents light-induced apoptotic cell death of photoreceptors in retinal degeneration in vivo. Nature Med 1997;3:346-9.
62 LaVail MM, Unoki K, Yasumura D, et al. Multiple growth factors, cytokines, and neurotrophins rescue photoreceptors from the damaging effects of constant light. Proc Natl Acad Sci USA 1992; 89:11249-53.

63 MacDonald ME, Gusella JF. Huntington's disease: translating a CAG repeat into a pathogenic mechanism. Curr Opin Neurobiol 1996;6:638-43.

64 Zeitlin S, Liu JP, Chapman DL, Papaioannou VE, Efstratiadis A. Increased apoptosis and early embryonic lethality in mice nullizygous for the Huntington's disease gene homologue. Nature Genet 1995;11:155-63.

65 Goldberg YP, Nicholson DW, Rasper DM, et al. Cleavage of huntingtin by apopain, a proapoptotic cysteine protease, is modulated by the polyglutamine tract. Nature Genet 1996;13:442-9.

66 Mangiarini L, Sathasivam K, Seller M, et al. Exon 1 of the $\mathrm{HD}$ gene with an expanded CAG repeat is sufficient to cause a progressive neurological phenotype in transgenic cause a progressive neurolo
mice. Cell $1996 ; 87: 493-506$.

67 Lakin ND, Weber P, Stankovic T, Rottinghaus ST, Taylor AM, Jackson SP. Analysis of the ATM protein in wild-type and ataxia telangiectasia cells. Oncogene 1996;13:2707-16. 68 Jongmans W, Artuso M, Vuillaume M, Bresil H, Jackson SP, Hall J. The role of ataxia telangiectasia and the DNA-dependent protein kinase in the p53-mediated cellular response to ionising radiation. Oncogene 1996;13:1133-8.

69 Rosen DR, Siddique T, Patterson D, et al. Mutations in $\mathrm{Cu} / \mathrm{Zn}$ superoxide dismutase gene are associated with familial amyotrophic lateral sclerosis. Nature 1993;362:5962

70 Rabizadeh S, Gralla EB, Borchelt DR, et al. Mutations associated with amyotrophic lateral sclerosis convert superoxide dismutase from an antiapoptotic gene to a proapoptotic gene: studies in yeast and neural cells. Proc Natl Acad Sci USA 1995;92:3024-8.

71 Gurney ME, Pu H, Chiu AY, et al. Motor neuron degeneration in mice that express a human $\mathrm{Cu} / \mathrm{Zn}$ superoxide distion in mice that express a human $\mathrm{Cu} / \mathrm{Zn}$ supe
mutase mutation. Science 1994;264:1772-5.

72 Busciglio J, Yankner BA. Apoptosis and increased generation of reactive oxygen species in Down's syndrome neurons in vitro. Nature 1995;378:776-69.

73 Olson L. The coming of age of the GDNF family and its receptors: gene delivery in a rat Parkinson model may have clinical implications. Trends Neurosci 1997;20:277-9.

74 Roses AD. The Alzheimer diseases. Curr Opin Neurobiol 1996;6:644-50.

75 Loo DT, Copani A, Pike CJ, Whittemore ER, Walencewicz AJ, Cotman CW. Apoptosis is induced by beta-amyloid in cultured central nervous system neurons. Proc Natl Acad Sci USA 1993;90:7951-5.

76 Peinemann F, Danner DJ. Maple syrup urine disease 1954 to 1993. F Inher Metab Dis 1994:17:3-15.

77 Gluckman P, Klempt N, Guan J, et al. A role for IGF-1 in the rescue of CNS neurons following hypoxic-ischemic injury Biochem Biophys Res Commun 1992;182:593-9.

78 Goto K, Ishige A, Sekiguchi K, et al. Effects of cycloheximide on delayed neuronal death in rat hippocampus Brain Res 1990;534:299-302.

79 Loddick SA, MacKenzie A, Rothwell NJ. An ICE inhibitor, z-VAD-DCB attenuates ischaemic brain damage in the Z-VAD-DCB attenuates ischaemi
rat. Neuroreport 1996;7:1465-8

80 Edwards AD, Yue X, Squier MV, et al. Specific inhibition of apoptosis after cerebral hypoxia-ischaemia by moderate post-insult hypothermia. Biochem Biophys Res Commun 1995;217:1193-9.

81 Aubert I, Ridet JL, Gage FH. Regeneration in the adult mammalian CNS: guided by development. Curr Opin Neurobiol 1995;5:625-35.

82 Karpati G, Lochmuller H, Nalbantoglu J, Durham H. The principles of gene therapy for the nervous system. Trends Neurosci 1996;19:49-54

83 Culver KW, Ram Z, Wallbridge S, Ishii H, Oldfield EH, Blaese RM. In vivo gene transfer with retroviral vectorproducer cells for treatment of experimental brain tumors. Science 1992;256:1550-2.

84 Weller M, Frei K, Groscurth $\mathrm{P}$, Krammer $\mathrm{PH}$, et al. Anti-Fas/APO-1 antibody-mediated apoptosis of cultured human glioma cells. Induction and modulation of sensitivity by cytokines. $\mathcal{F}$ Clin Invest 1994;94:954-64. 